\title{
Numerical Study of Supercritical R134a Heat Transfer in a Horizontal Ribbed Tube for Trans-Critical ORC Systems
}

\author{
Dabiao Wang', 2 , Hang Lu', Enjie Fang ${ }^{1}$, Lanlan $\mathrm{Li}^{3}$ \\ ${ }^{1}$ Fuzhou University, School of Mechanical Engineering and Automation, Fuzhou, Fujian, China \\ ${ }^{2}$ Key Laboratory of Fluid Power and Intelligent Electro-Hydraulic Control (Fuzhou University), Fuzhou, Fujian, China \\ ${ }^{3}$ College of Physics and Information Engineering, Fuzhou University, Fuzhou, Fujian, China
}

\begin{abstract}
Internally ribbed tubes can improve TORC (Trans-critical Organic Rankine Cycle) heat transfer economics and safety by improving the heat transfer coefficient and restricting buoyancy effects in horizontal flows. The heat transfer characteristics of supercritical organic fluids in internally ribbed tubes need to be more thoroughly understood. The present study calculated the flow and temperature fields in a horizontal ribbed tube to analyze the heat transfer enhancement of super critical R134a and the buoyancy effects on the heat transfer. The results show that the heat transfer enhancement near the pseudo critical point is mainly caused by the large specific heat effect in the boundary layer. The buoyancy enhances the radial direction velocities ( $x$ and $y$ directions) and reduces the axial speed ( $z$ direction) along the top of the horizontal tube. The lower axial speed reduces the turbulent kinetic energy and the top side heat transfer coefficient as a result. The simulation results were also compared with the heat transfer in a smooth horizontal tube and vertical ribbed tube with upwards flow. The results showed that the spiral follow induced by the internal ribs strongly restricts the buoyancy flow. Vertical upwards flow has a higher overall heat transfer coefficient and no circumferential temperature gradients, which improves the heat transfer economics and safety in TORC systems. Hence, vertical flow heat exchangers should be considered in TORC systems due to the improved heat transfer.
\end{abstract}

Keywords: Supercritical, heat transfer, R134a, internally ribbed tube, numerical, horizontal

Nomenclature

$b \quad$ rib width (mm)

$c_{p} \quad$ specific heat $\left(\mathrm{kJkg}^{-1} \mathrm{~K}^{-1}\right)$

$d \quad$ diameter $(\mathrm{mm})$

$e \quad$ rib width in axial direction (mm)

$G \quad$ mass flux $\left(\mathrm{kgm}^{2} \mathrm{~s}^{-1}\right)$

$g \quad$ gravity $\left(\mathrm{m} \mathrm{s}^{-2}\right)$

$h \quad$ enthalpy $\left(\mathrm{Jkg}^{-1}\right)$

$H \quad$ rig height (mm)

ke turbulent kinetic energy $\left(\mathrm{m}^{2} \mathrm{~s}^{-2}\right)$

$N \quad$ number of ribs

$\mathrm{Nu} \quad$ Nusselt number

$P \quad$ pressure $(\mathrm{MPa})$

$q \quad$ heat flux $\left(\mathrm{kWm}^{-2}\right)$

$s \quad$ pitch (mm)

$T \quad$ temperature $\left({ }^{\circ} \mathrm{C}\right)$

$u \quad$ velocity in $\mathrm{x}$ direction $\left(\mathrm{ms}^{-1}\right)$

$v \quad$ velocity in y direction $\left(\mathrm{ms}^{-1}\right)$

$V \quad$ velocity $\left(\mathrm{ms}^{-1}\right)$

$w \quad$ velocity in $\mathrm{z}$ direction $\left(\mathrm{ms}^{-1}\right)$

$\alpha \quad$ heat transfer coefficient $\left(\mathrm{W} \mathrm{m}^{-2} \mathrm{~K}^{-1}\right)$

$\lambda$ thermal conductivity $\left(\mathrm{Wm}^{-1} \mathrm{~K}^{-1}\right)$

$\mu \quad$ dynamic viscosity (Pa.s)

$\begin{array}{ll}\text { Subscripts } & \\ \text { b } & \text { bulk } \\ \text { cal } & \text { calculation } \\ \text { exp } & \text { experimental } \\ \text { hd } & \text { hydraulic diameter } \\ \text { in } & \text { inside } \\ \text { min } & \text { minimum } \\ \text { max } & \text { maximum } \\ \text { IRT } & \text { Internally ribbed tube } \\ \text { out } & \text { out side } \\ \text { pc } & \text { pseudo critical } \\ \text { ST } & \text { smooth tube } \\ \text { x } & \text { x direction } \\ \text { y } & \text { y direction } \\ \text { z } & \text { tube axial direction }\end{array}$

Acronyms

IRT

P1-P6

M01-M04

ORC

TORC 
$v \quad$ kinematic viscosity $\left(\mathrm{m}^{2} \mathrm{~s}^{-1}\right)$

$\rho \quad$ density $\left(\mathrm{kgm}^{-3}\right)$

$\Phi \quad$ thread angle $\left({ }^{\circ}\right)$

\section{Introduction}

ORC (Organic Rankine Cycle, ORC) power generation systems have developed quickly in recently years $[1,2]$ and has been widely adopted in solar energy[3], geothermal energy[4], bio-energy[5] and waste heat[6, 7] systems. TORC (Trans critical Organic Rankine Cycle) systems will be the next generation systems with higher thermal efficiencies and simpler system components than traditional ORC systems [8,9]. However, more research is needed to understand the supercritical organic heat transfer characteristics before TORC systems can be widely used in applications [10]. Supercritical organic heat transfer has two challenges with the need for more accurate heat transfer prediction correlations and the need for effective buoyancy restriction [11]. Accuracy correlations will lead to better supercritical heater designs and more stable systems while the buoyancy effects need to be restricted to improve the system safety by restricting the heat transfer deterioration due to the buoyancy effects.

Supercritical fluids have large property variations near the critical or pseudo critical points which complicate the supercritical fluid heat transfer and have led to three heat transfer models [12]. Supercritical heat transfer is difficult to predict, especially due to the buoyancy induced heat transfer deterioration, with many studies devoted to developing better heat transfer correlations $[13,14]$. However, studies have shown that the correlations are only accurate when compared with experimental data from the same author [15]. In addition, heat transfer correlations based on one supercritical fluid often are not accurate for another supercritical fluid [13]. Previous supercritical heat transfer research has focused on vertical water and $\mathrm{CO}_{2}$ flows for supercritical boilers and supercritical reactors [10]. TORC systems use different tubes layouts and sizes with few studies of organic supercritical fluid heat transfer for TORC systems. Tian et al. [16] experimentally investigated the heat transfer of a typical organic fluid (R134) in a horizontal smooth tube to build heat transfer correlations for TORC system designs. The studies used horizontal flow since the heat exchangers in most commercial ORC systems are horizontal. They found large temperature differences between the top and bottom tube surfaces due to the buoyancy effects which could lead safety issues due to organic fluid decomposition and tube failures. Every organic fluid has a safe operating temperature since the organic fluid decomposes at higher temperatures [17]. A sudden temperature increase due to heat transfer deterioration may lead to organic fluid decomposition. In addition, the large temperature differences between the top and bottom tube surfaces will produce thermal stresses which can lead to tube failure [18]. Therefore, Wang et al. [11] analyzed the heat transfer of supercritical R134a in a horizontal Internally Ribbed Tube (IRT) to improve the supercritical organic fluid heat transfer safety by restricting the buoyancy effects. They showed that the heat transfer in the IRT was about 4.61 times better along the top and 1.40 times better along the bottom than in a smooth tube. Thus, the buoyancy was strongly restricted so that the buoyancy effects threshold in the IRT was 20 times higher than in a smooth tube. The experimental data was also used to describe the supercritical R134a heat transfer characteristics. However, the flow and temperature fields in the IRT still need to be more thoroughly understood to describe the heat transfer characteristics observed in the experiments, especially the effects of the ribs and the buoyancy on the heat transfer. In addition, vertical flow heat transfer of super critical organic fluids in the IRT have not been analyzed before.

The present study presents a numerical study of the heat transfer of supercritical R134a in an IRT. The heat transfer enhancement characteristics are described quantitatively along with the effects of buoyancy and the ribs on the flow and temperature fields. The heat transfer is also compared with the heat transfer in a smooth horizontal tube and a vertical IRT with upwards flow to demonstrate the effects of the ribs and buoyancy. The results in this study provide guidance for supercritical heater designs in TORC systems.

\section{Numerical Approach}

\subsection{Analysis geometry and boundary conditions}

The IRT geometry used in the present study is the same as a previous experimental study [11] with the rib parameters given in Table 1. The IRT consisted of a $500 \mathrm{~mm}$ unheated section and a $2600 \mathrm{~mm}$ heated section with the axis in the $\mathrm{z}$ 
direction as shown in Fig. 1. The unheated section allowed the flow to become fully developed to avoid the inlet effects on heat transfer. The tube was made of the alloy steel SA-213T12 with the properties given in Table 2. In the experiment, the SA-213T12 properties at various axial positions were slightly difference due to the different temperatures. However, Li [19] showed that the tube property variations have very little effect on the heat transfer. When the SA-213T12 tube material was changed to SS304, which has relatively large property differences from those of SA-213T12 as shown in Table 2, the maximum predicted inner wall temperature differences were only $0.3 \mathrm{~K}$. Hence, the tube property variations with temperature were neglected in this study. The R134a properties at various temperatures were calculated using NIST Refprop 9.0 and imported into Fluent 18.2 through piecewise linear functions. The pressure loss in the internally rib is quite small, so the pressure loss effects on the properties were also neglected.

Table 1

Geometric dimensions of the IRT

\begin{tabular}{|c|c|c|c|c|c|c|c|c|c|}
\hline $\begin{array}{c}\text { Tube outer } \\
\text { diameter } \\
d_{\text {out }}(\mathrm{mm})\end{array}$ & $\begin{array}{c}\text { Maximum inner } \\
\text { diameter } \\
d_{\text {in, } \max }(\mathrm{mm})\end{array}$ & $\begin{array}{c}\text { Minimum inner } \\
\text { diameter } \\
d_{\text {in, min }}(\mathrm{mm})\end{array}$ & $\begin{array}{c}\text { Hydraulic } \\
\text { diameter } \\
d_{\text {in,hd }}(\mathrm{mm})\end{array}$ & $\begin{array}{c}\text { Number } \\
\text { of ribs } \\
N\end{array}$ & $\begin{array}{c}\text { Rib } \\
\text { height } \\
H(\mathrm{~mm})\end{array}$ & $\begin{array}{c}\text { Rib width (peripheral } \\
\text { direction) } \\
b_{1}(\mathrm{~mm})\end{array}$ & $\begin{array}{c}\text { Rib width (axial } \\
\text { direction) } \\
b_{2}(\mathrm{~mm})\end{array}$ & $\begin{array}{l}\text { Thread } \\
\text { angle } \\
\alpha\left({ }^{\circ}\right)\end{array}$ & $\begin{array}{c}\text { Pitch } \\
s(\mathrm{~mm})\end{array}$ \\
\hline 20 & 15.84 & 13.39 & 15.5 & 4 & 0.85 & 4.78 & 8.28 & 30 & 21.55 \\
\hline
\end{tabular}

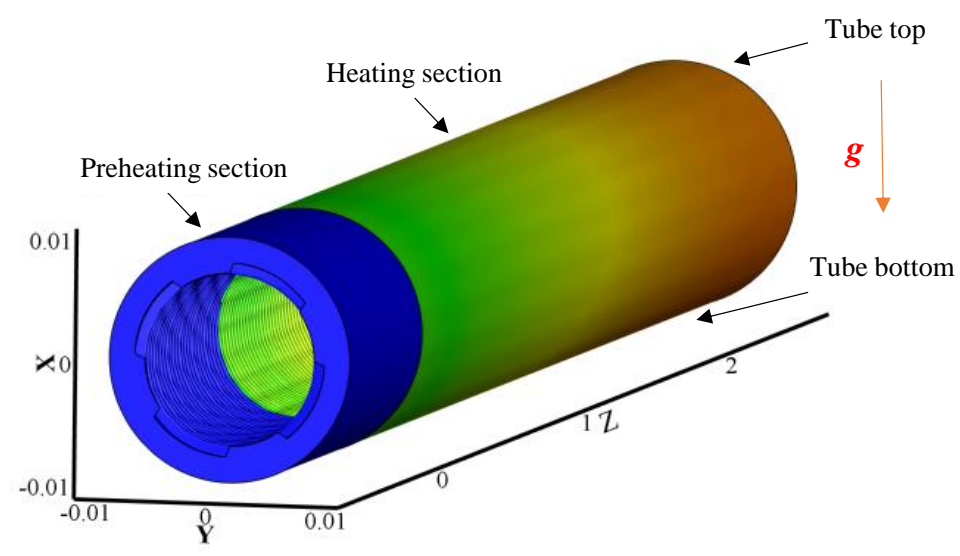

Table 2

Fig. 1. Geometric parameters of the IRT

Tube wall properties

\begin{tabular}{cccc}
\hline Material & $\boldsymbol{\rho}\left(\mathbf{k g m}^{-3}\right)$ & $\boldsymbol{c}_{p}\left(\mathbf{J k g} \mathbf{~ k}^{-1}\right)$ & $\lambda\left(\mathbf{W m} \mathbf{m}^{-1} \mathbf{k}^{-1}\right)$ \\
\hline SA-213T12 & 8700 & 450 & 45 \\
SS304 & 7900 & 500 & 16.3 \\
\hline
\end{tabular}

\subsection{Turbulence model}

The finite volume method was used to numerical solve the three-dimensional continuity equation, momentum equations and energy equation for the flow through the IRT. The equations are:

$$
\begin{aligned}
& \frac{\partial\left(\rho u_{\mathrm{j}}\right)}{\partial x_{\mathrm{j}}}=0 \\
& \frac{\partial\left(\bar{\rho} u_{\mathrm{j}} u_{\mathrm{i}}\right)}{\partial \mathrm{x}_{\mathrm{i}}}=\frac{\partial p}{\partial x_{\mathrm{i}}}+\frac{\partial\left(\overline{\overline{\mathrm{ij}}_{\mathrm{j}}}-\overline{\rho \mu_{\mathrm{i}}^{\prime \prime} \mu_{\mathrm{j}} "}\right)}{\partial x_{\mathrm{i}}}+\rho g_{\mathrm{i}} \\
& \frac{\partial\left(\bar{\rho} u_{\mathrm{j}} h\right)}{\partial x_{\mathrm{i}}}=\frac{\partial p}{\partial x_{\mathrm{i}}}\left(\frac{\lambda}{c_{p}} \frac{\partial h}{\partial \mathrm{x}_{\mathrm{j}}}\right)
\end{aligned}
$$


$\overline{\rho \mu_{\mathrm{i}}{ }^{\prime \prime} \mu_{\mathrm{j}}{ }^{\prime \prime}}$ in the momentum equation was calculated based on the Boussinesq hypothesis with the turbulent viscosity coefficient, $\mu_{\mathrm{t}}$ :

$$
-\overline{-\rho \mu_{\mathrm{i}}^{\prime \prime} \mu_{\mathrm{j}}^{\prime \prime}}=\mu_{\mathrm{t}}\left(\frac{\partial u_{i}}{\partial x_{\mathrm{j}}}+\frac{\partial u_{\mathrm{j}}}{\partial x_{\mathrm{i}}}-\frac{2}{3} k \delta_{\mathrm{ij}}\right)
$$

The turbulent viscosity coefficient is a function of the turbulent kinetic energy, $k$, and the turbulent energy dissipation rate, $\varepsilon$, as:

$$
\mu_{\mathrm{t}}=C_{\mu} f_{\mu} \rho k^{2} / \varepsilon
$$

A turbulence model was used to calculate $\varepsilon$ and $k$ to close the equations. Previous simulations of supercritical water in vertical IRTs $[20,21]$ have indicated that the SST $k-\omega$ model gives better predictions for supercritical fluids in IRTs and is accurate in the near-wall region. Hence, the SST model is used in present study. The $k$ and $\omega$ transport equations in the SST model [22] are:

$$
\begin{aligned}
& \frac{\partial\left(\bar{\rho} u_{\mathrm{i}} k\right)}{\partial x_{\mathrm{i}}}=\frac{\partial}{\partial x_{\mathrm{i}}}\left[\left(u+\frac{u_{\mathrm{t}}}{\sigma_{\mathrm{k}}}\right) \frac{\partial k}{\partial x_{\mathrm{j}}}\right]+G_{\mathrm{k}}-Y_{\mathrm{k}} \\
& \frac{\partial\left(\bar{\rho} u_{i} \omega\right)}{\partial x_{\mathrm{i}}}=\frac{\partial}{\partial x_{i}}\left[\left(u+\frac{u_{\mathrm{t}}}{\sigma_{\omega}}\right) \frac{\partial \omega}{\partial \mathrm{x}_{\mathrm{j}}}\right]+G_{\omega}-Y_{\omega}+D_{\omega}
\end{aligned}
$$

The pressure-velocity coupling used the SIMPLEC algorithm with all the calculations using the second-order upwind method. The inlet and outlet boundary conditions were a mass flow inlet and a pressure outlet. Gravity was set as $9.8 \mathrm{~ms}-2$ in the $\mathrm{x}$ direction as shown in Fig. 1. The IRT was heated electrically in the experiment; therefore, a volumetric heat source was applied to the heating section tube wall in the simulation. The convergence residuals for velocity, mass, and energy were set to 10-5 with the residuals for $\mathrm{k}$ and $\omega$ set to 10-9. The average outlet temperature was also used to monitor the convergence. The calculation was assumed to be converged when the residuals and the fluid outlet temperature remain unchanged and the heat balance was very small.

\subsection{Mesh independence}
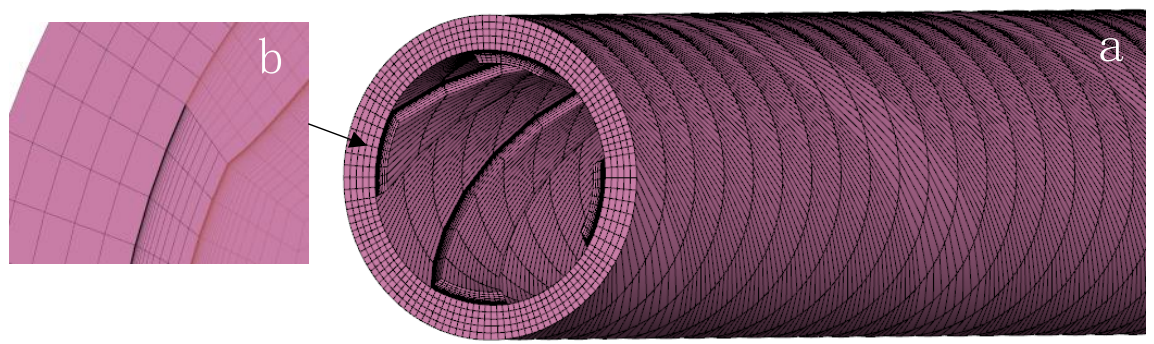

Fig. 2. Structured hexagonal mesh in the ITR (a) near the entrance and (b) enlarged view near the wall

Table 3

Mesh information

\begin{tabular}{ccccc}
\hline Mesh & First element thickness $(\mathrm{mm})$ & $\begin{array}{c}\text { Number of grid } \\
\text { layers near the wall }\end{array}$ & $\begin{array}{c}\text { Axial element } \\
\text { length }(\mathrm{mm})\end{array}$ & $\begin{array}{c}\text { Number of } \\
\text { elements } \\
\text { (millions) }\end{array}$ \\
\hline M01 & 0.01 & 15 & 8 & 310 \\
M02 & 0.005 & 25 & 8 & 401 \\
M03 & 0.002 & 25 & 8 & 450 \\
M04 & 0.001 & 30 & 8 & 560 \\
\hline
\end{tabular}


The grid used in present study was a structured hexagonal mesh generated by ICEM. As shown in Fig. 2, the elements were thinner on the fluid side near the rib top and in the rib channel to capture the flow information in the boundary layer. A grid independence test was used to show that the results were not affected by the grid quality. Four different meshes were constructed by reducing the near-wall element thickness as shown in Table 3 with tests for two working conditions. In case A, $P=4.26 \mathrm{MPa}$, $G=1000 \mathrm{kgm}^{-2} \mathrm{~s}^{-1}$, and $q=100 \mathrm{kWm}^{-2}$ while in case B, $P=4.26 \mathrm{MPa}, G=200 \mathrm{kgm}^{-2} \mathrm{~s}^{-1}$, and $q=15 \mathrm{kWm}^{-2} \mathrm{~s}^{-1}$. The results in Fig.3 show that the grid independence is related to the working conditions. In case B with the small $G$, the top wall temperatures predicted using the four meshes are exactly the same. In case A, the predictions show significant differences for the four meshes. In general, when the dimensionless distance from wall to the first element, $y^{+}\left(\mathrm{y}^{+}=u y / v\right)$, is smaller than 1 , the differences between the various models using the SST model are small. For the working conditions used in the present study, $G$ is less than $250 \mathrm{kgm}^{-2} \mathrm{~s}^{-1}$ which gives $y+$ of about 0.1 . Hence, the predictions for the various meshes are similar in Fig. $3 \mathrm{~b}$. Therefore, the M04 mesh with a first element thickness of $0.001 \mathrm{~mm}$ was used in the simulations.

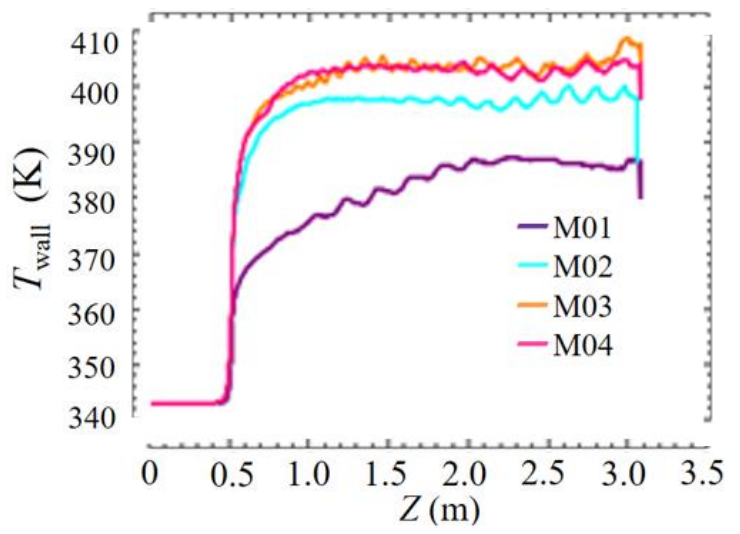

a. Case A

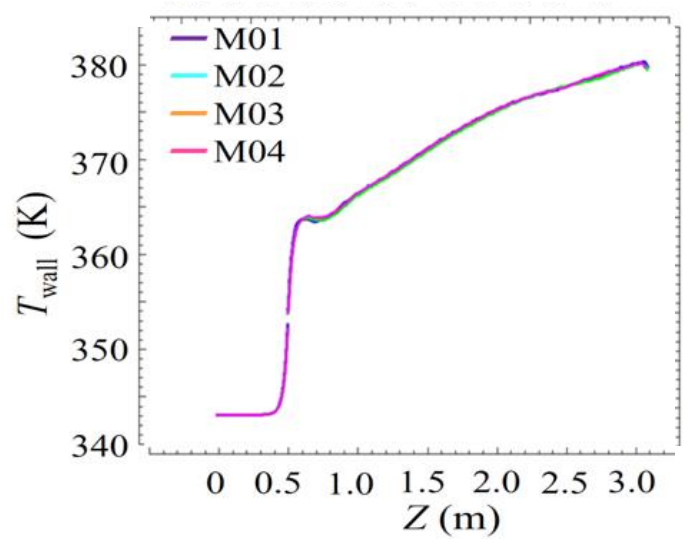

b. Case B

Fig. 3. Predicted IRT wall temperatures for the various meshes

\subsection{Model validation}

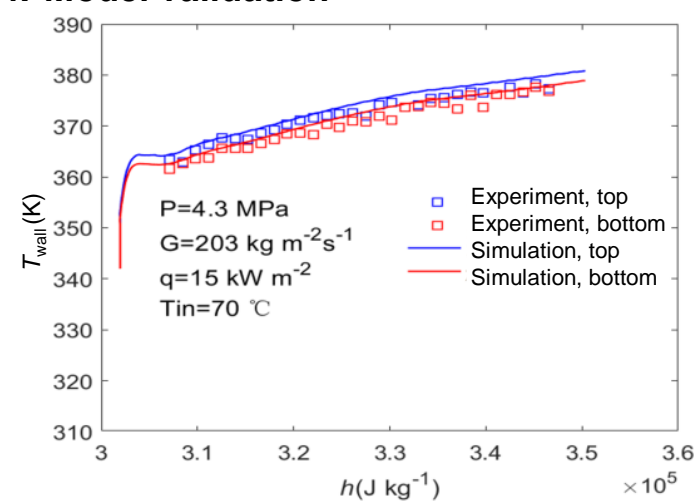

a. $q / G=0.07 \mathrm{~kJ} \mathrm{~kg}^{-1}$

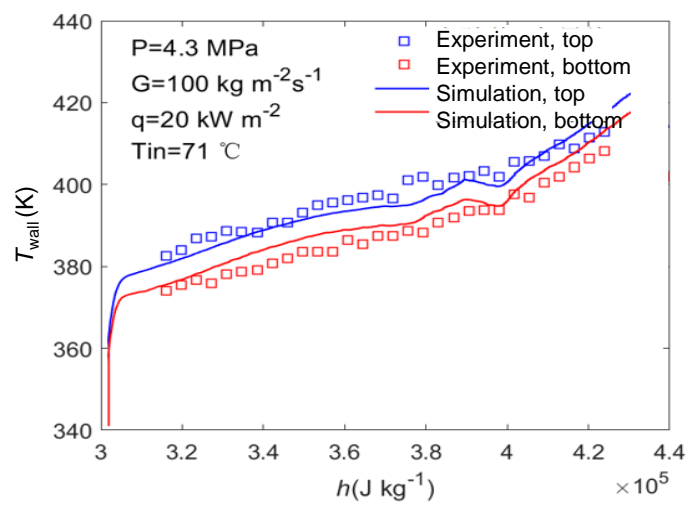

b. $q / G=0.2 \mathrm{~kJ} \mathrm{~kg}^{-1}$

Fig. 4. Predicted and measured results for various buoyancy conditions

Two groups of experimental results were used to compared with the predictions for various buoyancy effects on the heat transfer. The predictions are compared with the experimental data for the small buoyancy effect condition of $q / G=0.07 \mathrm{~kJ} \mathrm{~kg}^{-1}$ are shown in Fig.4a with those for $q / G=0.2 \mathrm{~kJ} \mathrm{~kg}^{-1}$ shown in Fig.4.b. The simulations accurately reflect the wall temperature variations for both conditions. The maximum difference between the predicted and measured wall temperatures is less than $3 \mathrm{~K}$, which is close to the thermocouple measurement accuracy $( \pm 1 \mathrm{~K})$ used in the experiment. Therefore, the simulation results in the present study are acceptable.

\section{Results and Discussion}




\subsection{Heat transfer enhancement characteristics}

The basic supercritical R134a heat transfer enhancement characteristics in the IRT were described in a previous experimental study [23]. The enhanced heat transfer will lead to smaller heat exchangers and a better TORC heat transfer economics. Hence, a thorough understanding of the enhancement mechanisms is needed to further improve the heat transfer. Jackson et al. [24] conducted a qualitative analysis of supercritical water heat transfer enhancement in a smooth tube based on experimental data and boundary layer theory. He concluded that the mechanisms are mainly related to two reasons. Firstly, the viscosity decreases near the pseudo critical point as shown in Fig. 5, which increases the turbulent kinetic energy near the wall. Secondly, the thermal conductivity has a large peak near the pseudo critical point, which reduces the thermal resistance in the boundary layer. The present study presents additional quantitative analyses of the supercritical R134a heat transfer enhancement mechanism in the IRT based on the simulation results.

Results are presented for a typical working condition ( $P=4.26 \mathrm{MPa}, G=200 \mathrm{kgm}^{-2} \mathrm{~s}^{-1}$, and $\left.q=20 \mathrm{kWm}^{-2}\right)$. The effects are illustrated using two cases with inlet temperatures of $70^{\circ} \mathrm{C}$ and $95^{\circ} \mathrm{C}$ to expand the bulk enthalpy, $h_{\mathrm{b}}$, range, as shown in Fig.6. The top and bottom wall temperatures for the two cases coincide after the entrance effect as shown in Fig. 6 . The heat transfer coefficient variations along the bottom , $\alpha_{\text {bottom }}$, with the bulk enthalpy, $h_{b}$, for this working condition are shown in Fig.7. The inverted ' $V$ ' shape heat transfer coefficient variation is due to the supercritical fluid heat transfer enhancement.

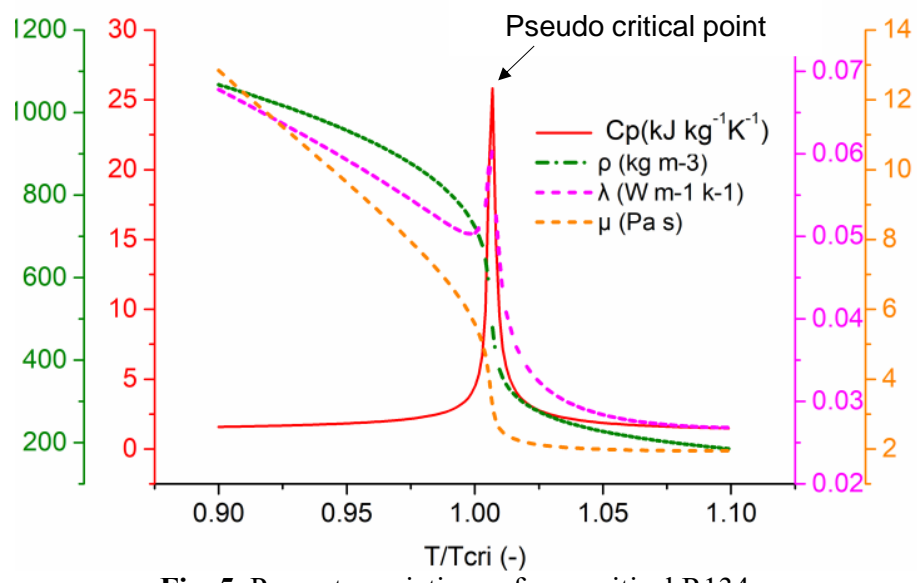

Fig. 5. Property variations of supercitical R134a

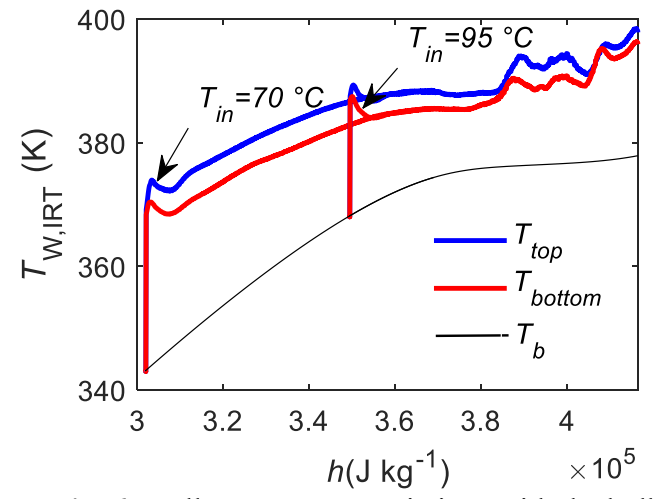

Fig. 6. Wall temperature variations with the bulk enthalpy

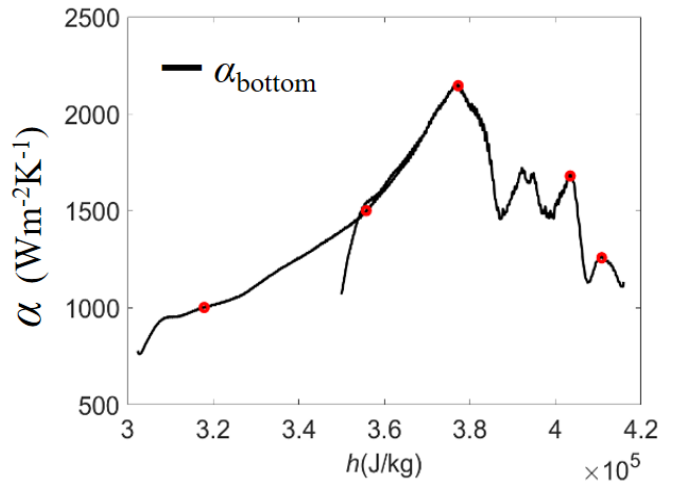

Fig. 7. Heat transfer coefficient variations along the bottom with the bulk enthalpy

The bulk enthalpies at five axial positions, P1-P5, show the gradual disappearance of the heat transfer enhancement. The bulk

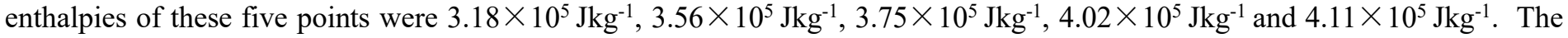
wall temperatures increase along these five positions and the corresponding heat transfer coefficient P3, $\alpha_{3}$, is greatest with the rest decreasing from $\alpha_{4}$ to $\alpha_{2}$ to $\alpha_{5}$ to $\alpha_{1}$. The fluid temperature variations from the wall to the tube center at these five axial positions are shown in Fig.8a. The fluid temperature decreases rapidly in a very thin boundary layer (less than $0.1 \mathrm{~mm}$ thick) close to the 
tube wall. Outside this thin layer, the temperature variation is relatively gentle which indicates that the boundary layer near the wall provides the primary resistance to the heat transfer. The flow and physical property information in the boundary layer is further analyzed by changing the abscissa from a linear coordinate to a logarithmic abscissa in Fig.8b.

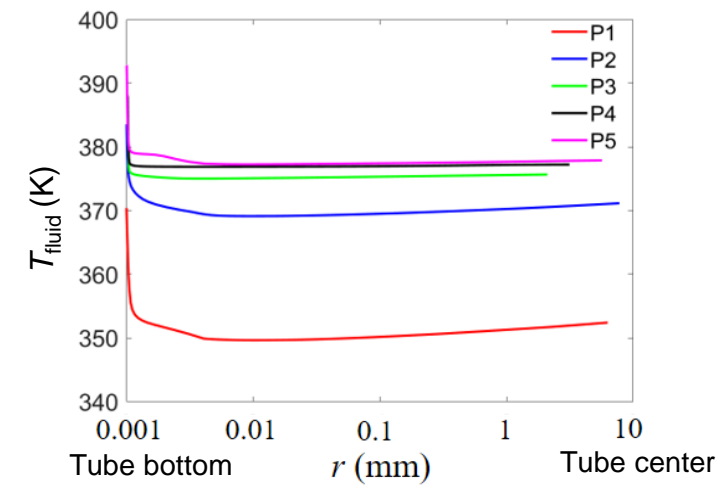

a. Linear coordinates

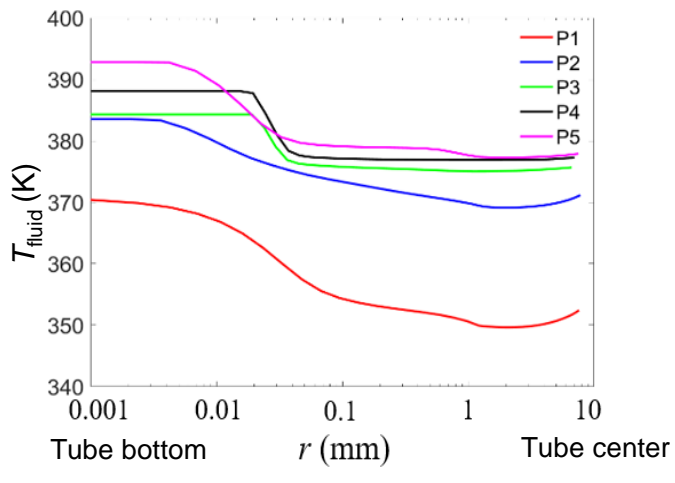

b. Logarithmic coordinates

Fig. 8. Fluid temperature variations in the radial direction

Both the turbulent kinetic energy and fluid properties in the boundary layer significantly affect the heat transfer. The turbulent kinetic energy variations in the radial direction at the five axial positions are shown in Fig.9.. The turbulent kinetic energy at P1 and P2 are similar in the boundary layer. The turbulent kinetic energy at P3 then increases rapidly at $\mathrm{y}+<30$ from the wall, which enhances the heat transfer. The turbulent kinetic energy at P4 and P5 are higher than at P3, but the heat transfer coefficient at P3 is higher than those at P4 and P5, which suggests that the turbulent kinetic energy distribution in the boundary layer is not the decisive factor for the heat transfer enhancement for these conditions. The physical parameters that affect the heat transfer include the viscosity, density, thermal conductivity and specific heat. The viscosity variation in the radial direction is shown in Fig.10. A smaller viscosity reduces the bottom viscous layer thickness in the boundary layer and reduces the turbulent energy dissipation in the transition layer, which enhances the energy transfer from the wall to the mainstream. However, the viscosities decrease from $\mathrm{P} 1$ to $\mathrm{P} 5$, so this trend differs from the "inverted V" heat transfer enhancement variation.

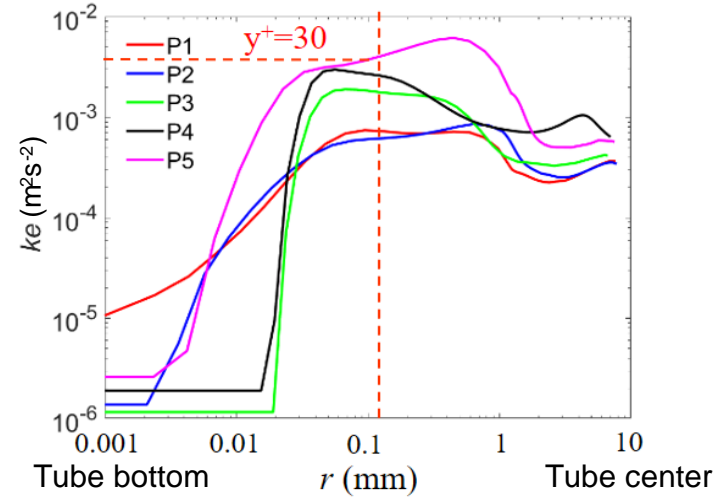

Fig. 9. Turbulent kinetic energy variations in the radial direction at the five points

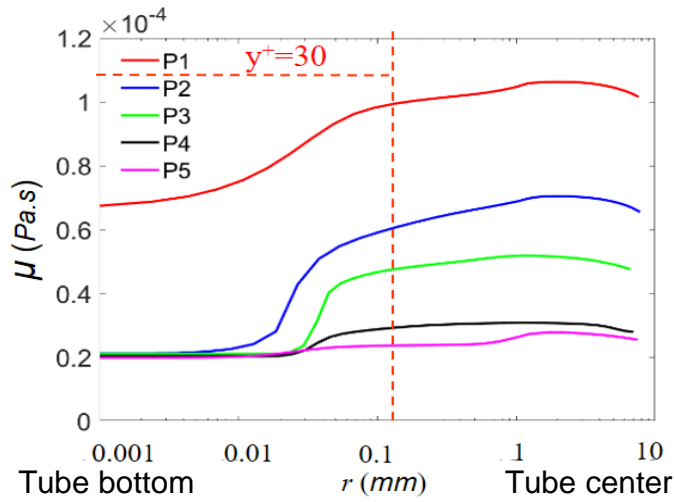

Fig. 10. Visicosity variations in the radial direction at the five points

The thermal conductivity variations at the five axial positions are shown in Fig.11.. A higher thermal conductivity reduces the thermal resistance of the bottom viscous layer which enhances the heat transfer. The thermal conductivity has a peak in the boundary layer at P3 which increases the heat enhancement at P3. However, the thermal conductivities at P1 and P2 are higher than those at P4 and P5, while the heat transfer coefficients at P4 and P5 are higher than those at P2 and P1. Thus, the heat transfer coefficient variations are not consistent with the thermal conductivity variations which suggests that the thermal conductivity changes are not the most important factor affecting the heat transfer. The specific heat variations are then shown in Fig. 12. The specific heat at $\mathrm{P} 1$ changes smoothly in the radial direction without a peak. The specific heat variations at P2-P5 have peaks with the peak positions gradually moving toward the mainstream from P2 to P5. The trend in the integral of $c_{p}$ integrated over $y^{+}$of 0 - 
30 in the boundary layer shown in Fig. 13 are quite consistent with the trends in the heat transfer coefficients which indicated that the variation of $\mathrm{cp}$ in the boundary layer is a key factor affecting the heat transfer enhancement. The result is similar to the conclusion obtained by Li [19] who also analyzed the effects of changes in these four fluid properties to show that $c p$ had the greatest effect on the forced convection heat transfer. For a wider range of $\mathrm{y}^{+}$, the average $\mathrm{c}_{\mathrm{p}}$ at $\mathrm{P} 4$ exceeds that at P3 which indicates that the main influence of $c_{p}$ is within the boundary layer rather than over the entire radial direction. Therefore, the heat transfer enhancement of supercritical organic working fluids in the IRT is mainly caused by the cumulative effect of $c_{\mathrm{p}}$ in the boundary layer.

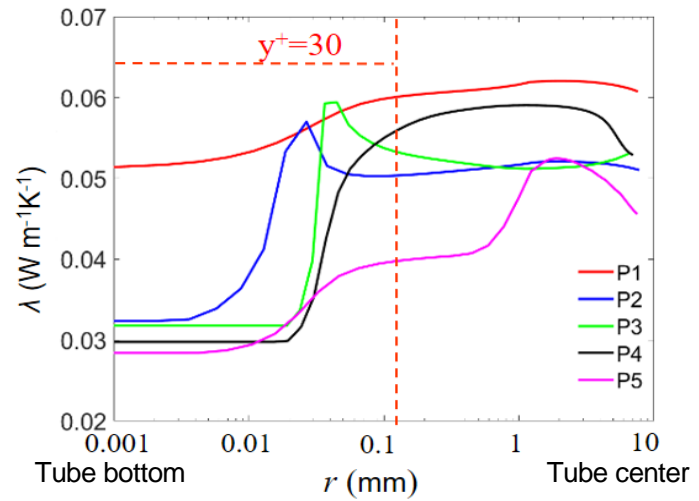

Fig. 11. Thermal conductivity variations in the radial direction

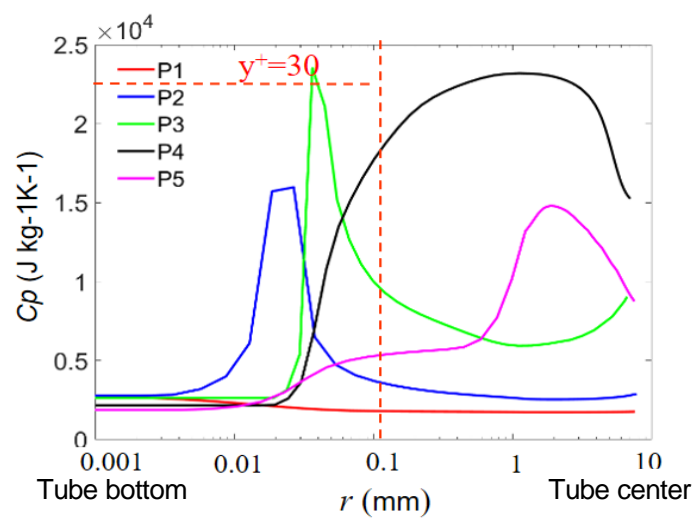

Fig. 12. Specific heat variations in the radial direction

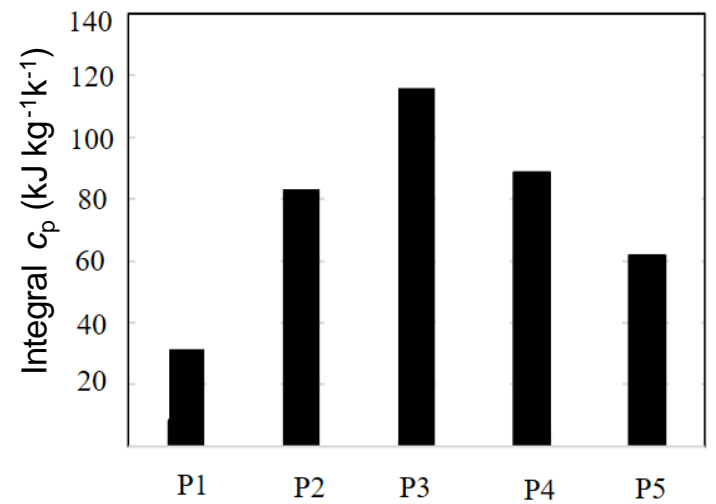

Fig. 13. Integral of the specific heat across the boundary layer $(y+<30)$ at different axial positions.

\subsection{Buoyancy effects}

The temperature differences between the top and bottom surfaces of a horizontal tube were observed previously with a prediction model developed to correlate the effects of buoyancy on the heat transfer [23]. In this section, the mechanism for the buoyancy effect on heat transfer is further analyzed using the flow and temperature fields from the simulation results.

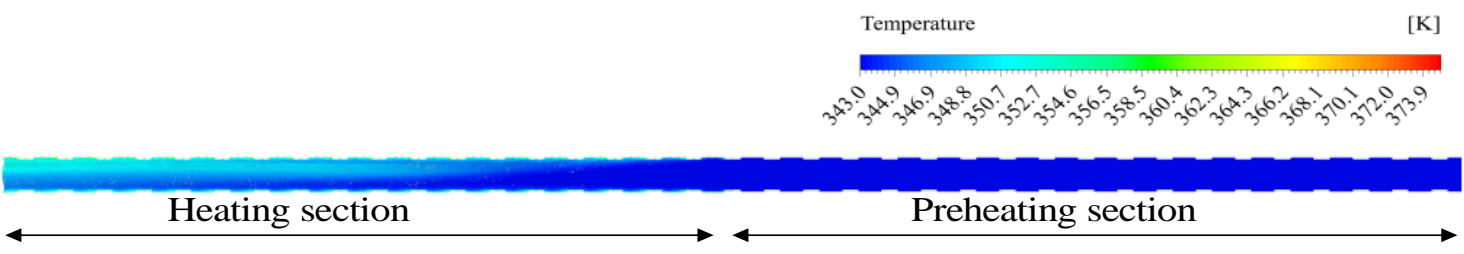

Fig. 14. Temperature distribution along $\mathrm{y}=0$

The fluid temperature distribution along the $y=0$ plane for $P=4.26 \mathrm{MPa}, G=200 \mathrm{kgm}^{-2} \mathrm{~s}^{-1}$, and $q=20 \mathrm{kWm}^{-2}$ is shown in Fig. 14. The temperature distribution in the unheated preheating section is uniform, with significant temperature stratification found between the top and bottom of the IRT in the heating section due to the buoyancy effects. The flow and temperature fields at axial 
position P6 ( $z=1.2 \mathrm{~m})$ are used to demonstrate the buoyancy effect in detail. The P6 section temperature distribution has significant stratification and asymmetry in the gravitational direction as shown in Fig. 15. The fluid temperatures in the top half are higher than in the bottom half and the temperatures in the left half are higher than in the right half. The temperatures are not symmetric because the fluid temperature near the tube wall is higher than in the tube center. The supercritical fluid density decreases sharply near the pseudo critical point, as shown in Fig. 5. Hence, the temperature difference increases the density difference to create the density distribution at P6 shown in Fig. 16. The density difference then produces buoyancy in the gravitational field which drives the lower density fluid in the horizontal tube towards the top which creates an even larger temperature difference between the top and bottom surfaces. This process continues until the buoyancy flow reaches equilibrium. The higher fluid temperature on the right side is due to the counterclockwise rotation of the IRT spiral used in the present study. The buoyancy flow has the same flow direction as the spiral flow on the right side and the opposite direction on the left. Thus, as seen in Fig. 17, the overall velocity, $V$, on the right is higher than that on the left. Therefore, the heat transfer coefficient on the right side is higher as the fluid velocity increases, resulting in a lower fluid temperature. The fluid in the IRT produces a complex vortex flow due to the superposition of the buoyant flow and the spiral flow as shown in Fig. 17.

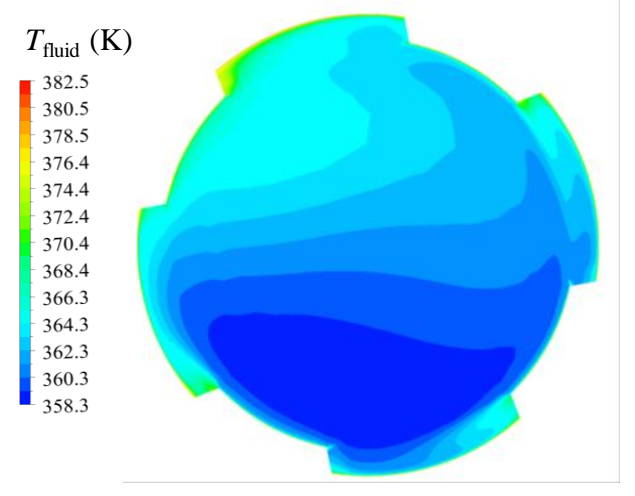

Fig. 15. Temperature

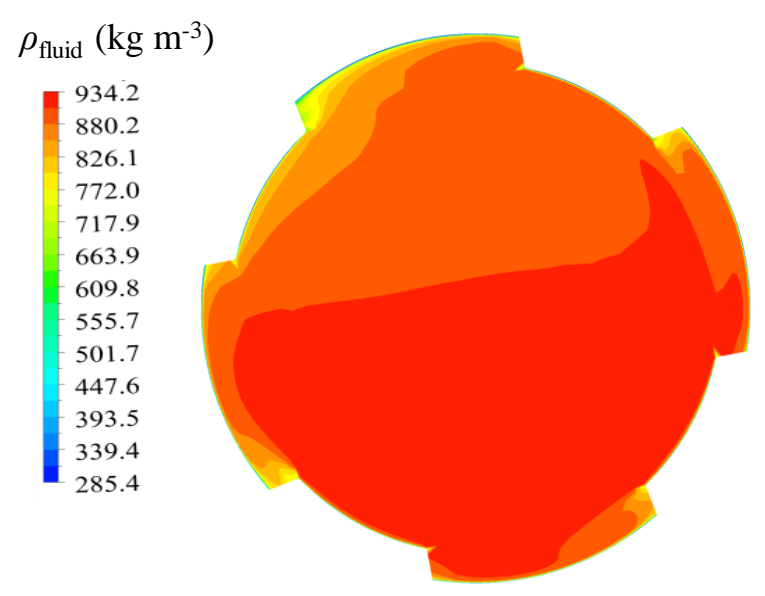

Fig. 16. Density

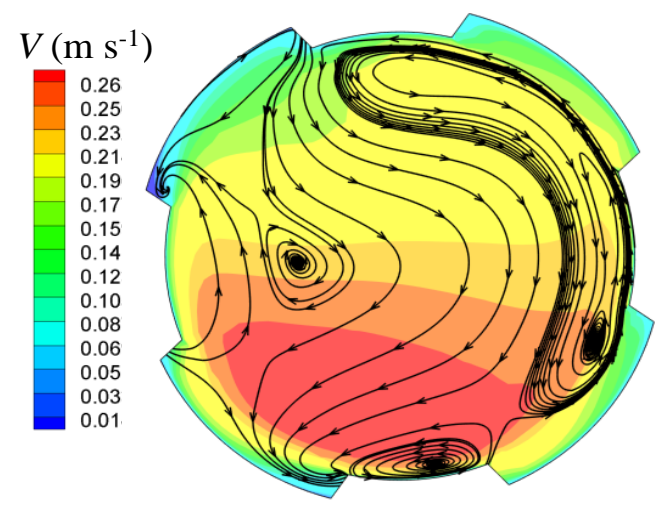

Fig. 17. Velocity

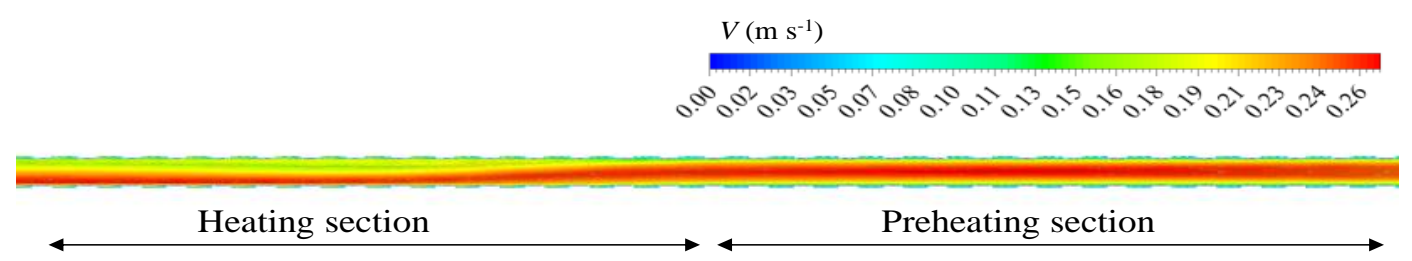


Fig. 18. Velosity in the $y=0$ plane

In addition to the temperature stratification, the velocity in the $y=0$ plane is also stratified, as shown in Fig. 18 . This phenomenon is significantly different from that in subcritical two-phase flow. In subcritical two-phase flow, the gas velocity is much higher than the liquid velocity along the bottom for the same pressure gradient between the inlet and the outlet. However, the velocity of the gas-like fluid in a supercritical fluid is lower than that of the liquid-like fluid. The flow field information at P6 with and without buoyancy effects was used to further analyze this feature of supercritical fluids as shown in Fig. 19 and Fig. 20 , where $V$ is the total velocity and $u, v$, and $w$ are the component velocities in the $\mathrm{x}, \mathrm{y}$, and $\mathrm{z}$ directions. The results do not show any gas-liquid interface in the supercritical fluid. The $u$ and $v$ distributions without buoyancy are symmetrical as shown in Fig. 20 a and $\mathrm{b}$, while the $u$ and $v$ distributions with buoyancy are not symmetrical with the maximum $u$ increasing from 0.07 without buoyancy to $0.11 \mathrm{~ms}^{-1}$ with buoyancy while the maximum $v$ increases from 0.07 to 0.1 as shown in Fig. 19a and b. The increasing $u$ and $v$ reduce $w$, especially along the top of the horizontal tube as shown by comparing Fig. 19c and Fig. 20c. The average velocities at P6 with and without buoyancy are given in Table 4 . The average $u$ and $v$ with buoyancy are higher than without buoyancy. Hence, the buoyancy and the spiral flow increase $u$ and $v$ in the horizontal tube, which then reduces $w$, especially along the top, which in turn then leads to a lower overall velocity in the top half of the tube.
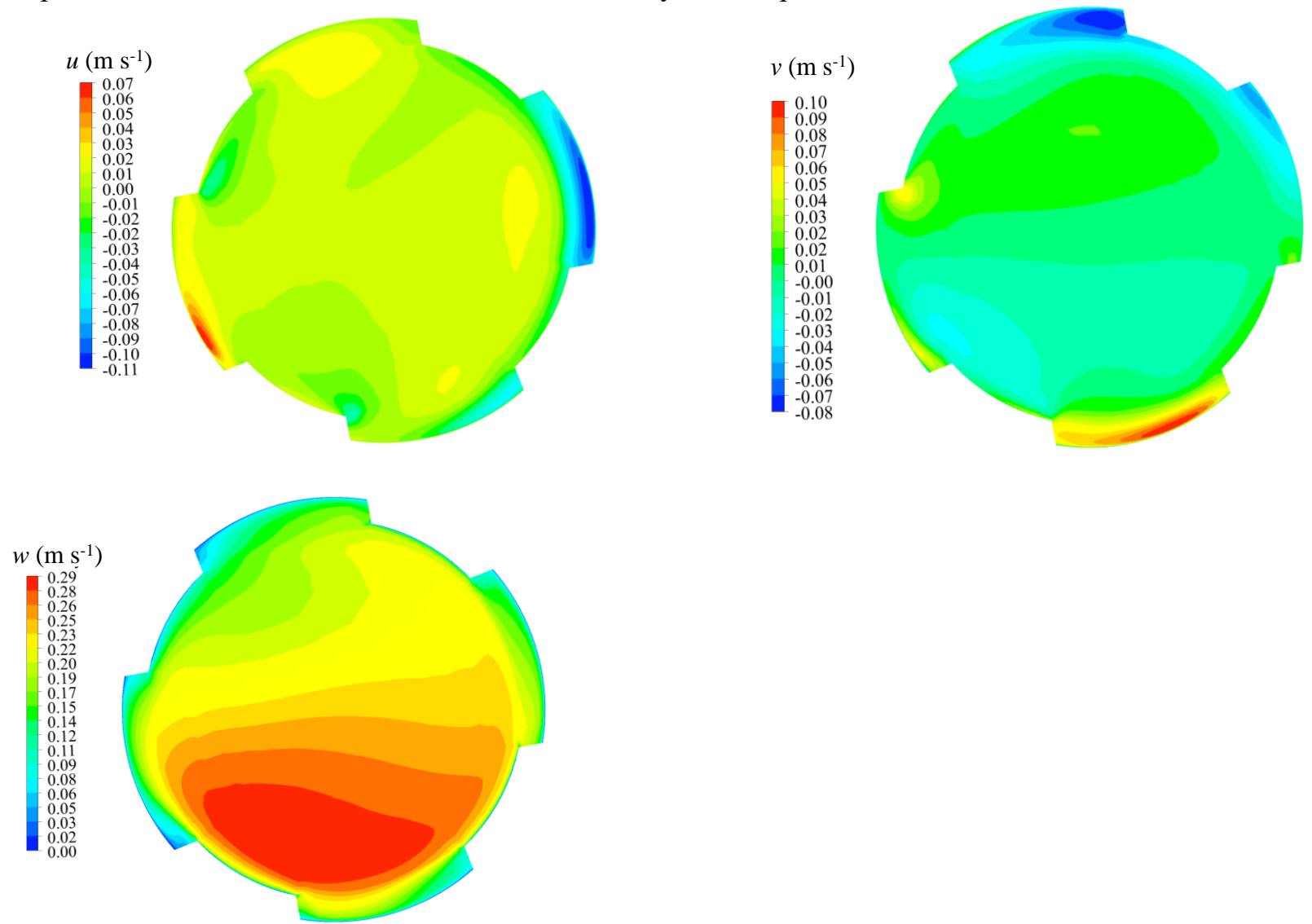

Fig. 19. Flow fields at $\mathrm{P} 6$ with buoyany (a. $u$ velocity, b. $v$ velocity, c. $w$ velocity ) 

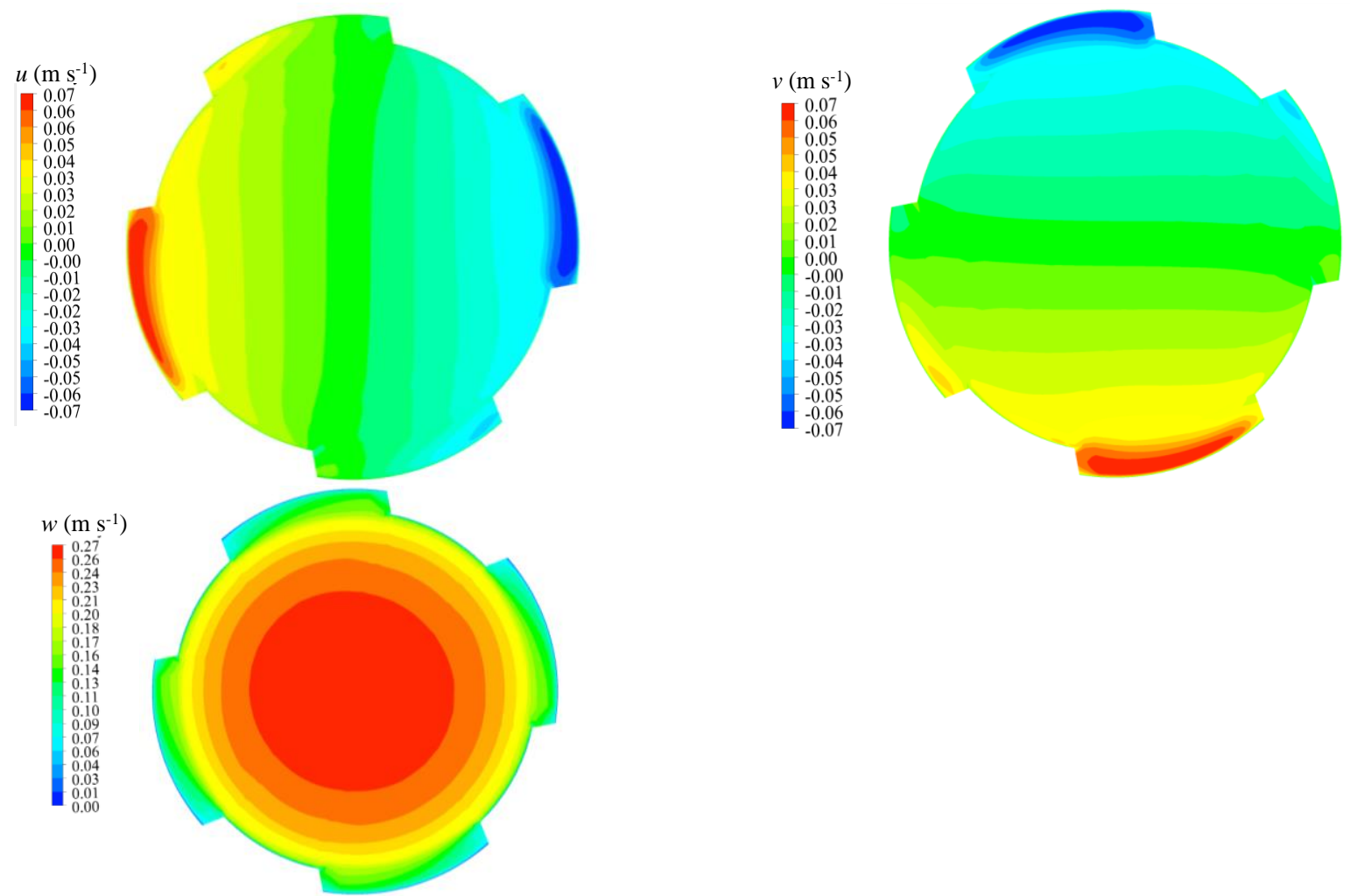

Fig. 20. Flow field at P6 without buoyancy (a. $u$ velocity, b. $v$ velocity, c. $w$ velocity)

Table 4

Velocities at P6 with and without buoyancy effects

\begin{tabular}{ccccc}
\hline & $u\left(\mathrm{~ms}^{-1}\right)$ & $v\left(\mathrm{~ms}^{-1}\right)$ & $w\left(\mathrm{~ms}^{-1}\right)$ & $\mathrm{V}\left(\mathrm{ms}^{-1}\right)$ \\
\hline Buoyancy & 0.001 & -0.0006 & 0.233 & 0.234 \\
No buoyancy & 0.00015 & 0.0001 & 0.235 & 0.237 \\
\hline
\end{tabular}

This velocity distribution then significantly affects the heat transfer. Fig.21 shows the radial distribution of the turbulent kinetic energy from the top of the tube to the bottom at five axial positions. At the five axial positions, the turbulent kinetic energy near the top is lower than near the bottom. The turbulent kinetic energy reduction near the top then results in further reduction of the heat transfer coefficient along the top.

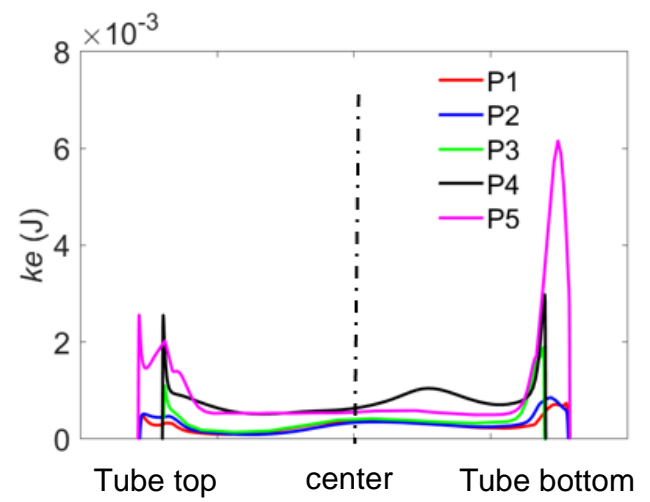

Fig. 21. Turbulent kinetic energy distribution in the 


\subsection{Comparisons with a smooth tube}

radial direction at various positions along the IRT.

The flow and heat transfer in a smooth tube with the same hydraulic diameter $\left(d_{\mathrm{in}}=15 \mathrm{~mm}\right)$ as the IRT was analyzed to further show the internal rib effects on the heat transfer. The wall temperatures in the IRT and in a smooth tube are shown in Fig. 22 for $P$ $=4.26 \mathrm{MPa}, G=200 \mathrm{kgm}^{-2} \mathrm{~s}^{-1}$ and $q=20 \mathrm{kWm}^{-2}$. The temperature differences between the top and bottom of the IRT are smaller than in the smooth tube. The smooth tube flow field driven by buoyancy at the position P6 has symmetrical vortices on the left and right sides and along the top as shown in Fig. 23, with the unsymmetrical spiral flow in the IRT caused by buoyancy formed a complex asymmetric flow field as shown in Fig. 17. Hence, the spiral flow has a restraining effect on the buoyancy and reduces the temperature difference between the top and bottom surfaces. The heat transfer coefficient in the IRT is higher than that in a smooth tube due to the smaller wall temperatures in the IRT. The turbulent kinetic energies in the two tubes at P6 are shown in Fig. 24. The turbulent kinetic energy near the wall in the IRT is significantly higher than in the smooth tube. Thus, the spiral flow in the IRT reduces the temperature difference between the top and bottom surfaces by suppressing the buoyancy effect and improves the overall heat transfer coefficient by increasing the turbulent kinetic energy near the wall.

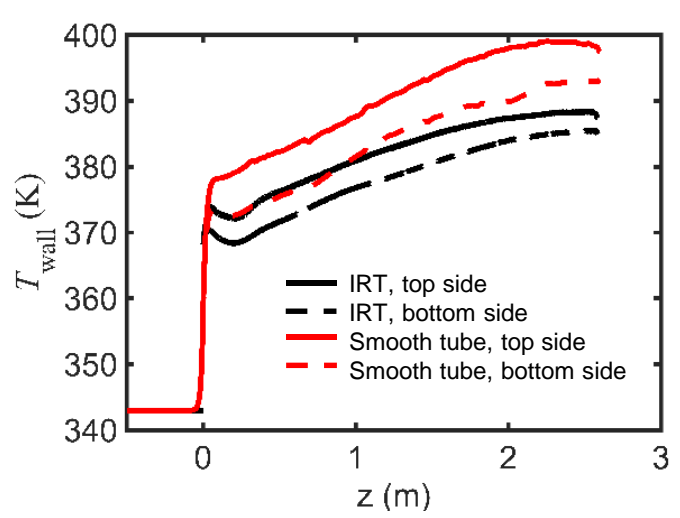

Fig. 22. Top and bottom wall temperatures for an IRT tube and a smooth tube.

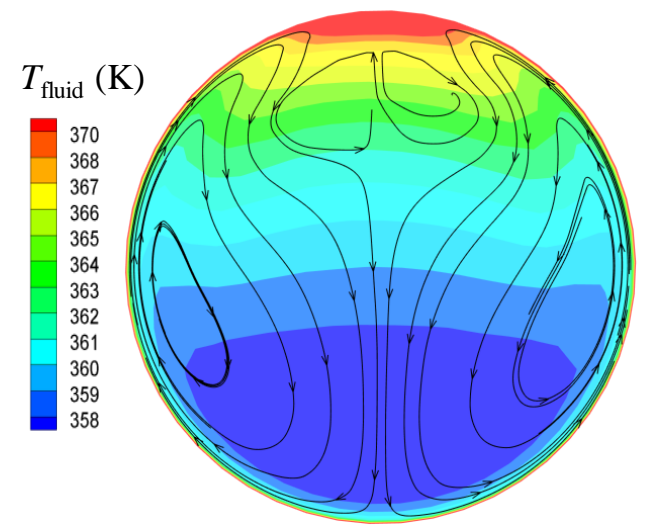

Fig. 23. Flow and temperature fields at $\mathrm{P} 6$ for flow in the smooth tube.

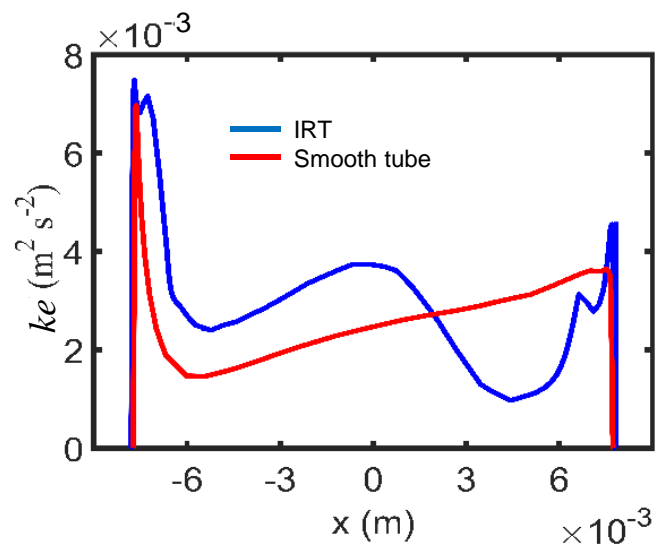

Fig. 24. ke distribtuions at $\mathrm{P} 6$ for the smooth tube and the IRT

\subsection{Comparison of horizontal and vertical orientations}

Although the majority of ORC system heat exchangers are currently horizontal flow layouts, in some special areas, vertical flow heat exchanger arrangements are also an option. Therefore, this section compares the heat transfer rates in IRT tubes with horizontal and vertical upward flow configurations. The wall temperatures for horizontal and vertical upward flows are compared in Fig. 25 for $P=4.26 \mathrm{MPa}, G=200 \mathrm{kgm}^{-2} \mathrm{~s}^{-1}$ and $q=20 \mathrm{kWm}^{-2}$. The IRT wall temperatures for the vertical upward flow are higher than the bottom temperature and lower than the top temperature in the horizontal IRT tube. Since the buoyancy direction in the vertical upward flow is the same as the flow direction, the flow and temperature fields are symmetrical with no wall temperature gradient in the circumferential direction, as shown in Fig. 26. The average heat transfer coefficient for the vertical flow is higher 
than the average heat transfer coefficient along the bottom and top surfaces of the horizontal configuration. Therefore, the vertical flow configuration has no circumferential wall temperature variation and higher average heat transfer coefficients which will improve the economics and safety of TORC systems, so the vertical configuration should be considered in future TORC system designs.

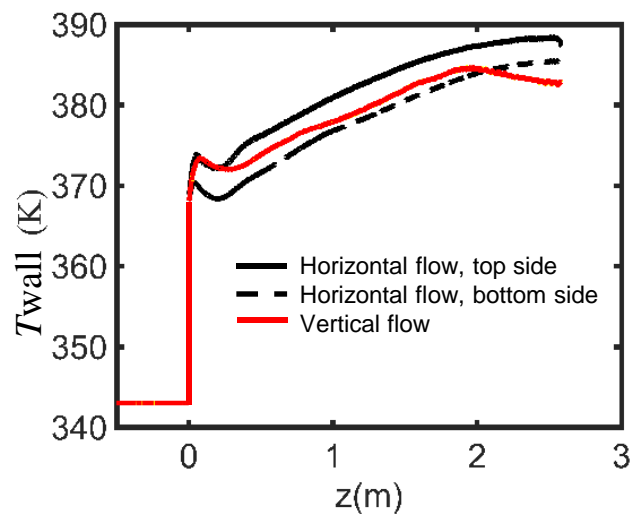

Fig. 25. Tube wall temperatures for horizontal and vertical flows in the IRT

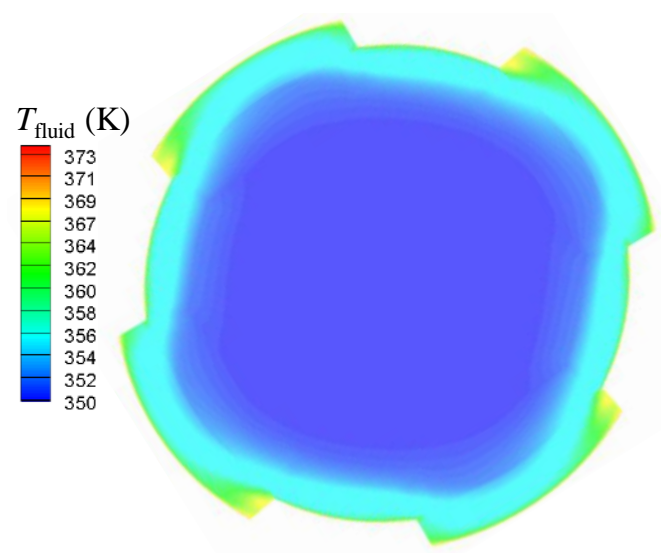

Fig. 26. Fluid termperature distribution at $P 1$ for the vertical flow configuration.

\section{Conclusions}

The present study predicted the temperature distributions and the heat transfer coefficients of super critical R134a in a horizontal internally ribbed tube to analyze the heat transfer characteristics based on the flow and temperature distributions. The simulation results were also used to compared the heat transfer coefficients in the horizontal IRT tube with those in a horizontal smooth tube and a vertical internally ribbed tube with upwards flow to show the rib and buoyancy effects on heat transfer. The conclusions are:

(1) The heat transfer enhancement near the pseudocritical point is mainly caused by variations of $\mathrm{cp}$ in the boundary layer.

(2) The temperature difference between the top and bottom surfaces is caused by buoyancy. The turbulent energy near the tube wall strongly affects the heat transfer coefficient differences along the top and bottom surfaces.

(3) The internal ribs restrict the buoyancy effects by inducing the spiral flow.

(4) Vertical upward flow in the IRT has a higher average heat transfer coefficient than in the horizontal IRT tube with no circumferential temperature variation which improves the heat transfer economics and safety of the TORC system.

\section{Acknowledgements:}

This work was supported by the Science Foundation of the Fujian Province, China (No. 2020J01453), the Fujian Province Young Middle-aged Teacher Education Research Project (No. JAT190004) and the National Natural Science Foundation of China (No. 51806117).

\section{References}

[1] Wang D, Ma Y, Tian R, Duan J, Hu B, Shi L. Thermodynamic evaluation of an ORC system with a Low Pressure Saturated Steam heat source. Energy. 2018;149:375-85.

[2] Wang D, Dai X, Wu Z, Zhao W, Wang P, Hu B, Shi L. Design and testing of a $340 \mathrm{~kW}$ Organic Rankine Cycle system for Low Pressure Saturated Steam heat source. Energy. 2020:118380.

[3] Oyekale J, Petrollese M, Cau G. Multi-objective thermo-economic optimization of biomass retrofit for an existing solar organic Rankine cycle power plant based on NSGA-II. Energy Reports. 2020;6:136-45.

[4] Yamaguchi T, Sasaki S, Momoki S. Experimental study for the small capacity organic Rankine cycle to recover the geothermal energy in Obama hot spring resort area. In: Chowdhury H, Rasul M, Alam F, Chowdhury A, Jazar R, editors. 2nd International Conference on Energy and Power2019. p. 389-95. 
[5] Rentizelas A, Karellas S, Kakaras E, Tatsiopoulos I. Comparative techno-economic analysis of ORC and gasification for bioenergy applications. Energy Conversion And Management. 2009;50:674-81.

[6] Zhu S, Zhang K, Deng K. A review of waste heat recovery from the marine engine with highly efficient bottoming power cycles. Renewable \& Sustainable Energy Reviews. 2020;120.

[7] Lion S, Vlaskos I, Taccani R. A review of emissions reduction technologies for low and medium speed marine Diesel engines and their potential for waste heat recovery. Energy Conversion and Management. 2020;207.

[8] Xiao S, Chen X, Qi L, Liu Y. Analysis of a supercritical organic Rankine cycle for low-grace waste heat recovery. Proceedings of the Institution of Civil Engineers-Energy. 2020;173:3-12.

[9] Moloney F, Almatrafi E, Goswami DY. Working fluid parametric analysis for recuperative supercritical organic Rankine cycles for medium geothermal reservoir temperatures. Renewable Energy. 2020;147:2874-81.

[10] Wang D, Tian R, Zhang Y, Li L, Ma Y, Shi L, Li H. Heat transfer investigation of supercritical R134a for trans-critical organic Rankine cycle system. Energy. 2019;169:542-57.

[11] Wang D, Tian R, Li L, Dai X, Shi L. Heat transfer of R134a in a horizontal internally ribbed tube and in a smooth tube under super critical pressure. Applied Thermal Engineering. 2020;173.

[12] Mokry S, Pioro I, Kirillov P, Gospodinov Y. Supercritical-water heat transfer in a vertical bare tube. Nuclear Engineering and Design. 2010;240:568-76.

[13] Huang D, Wu Z, Sunden B, Li W. A brief review on convection heat transfer of fluids at supercritical pressures in tubes and the recent progress. Appl Energy. 2016;162:494-505.

[14] Gschnaidtner T, Schatte GA, Kohlhepp A, Wang Y, Wieland C, Spliethoff H. A new assessment method for the evaluation of supercritical heat transfer correlations, particularly with regard to the "multiple/no solutions" problem. Thermal Science and Engineering Progress. 2018;7:267-78.

[15] Cheng X, Yang Y, Huang S. A simplified method for heat transfer prediction of supercritical fluids in circular tubes. Annals of Nuclear Energy. 2009;36:1120-8.

[16] Tian R, Wang D, Zhang Y, Ma Y, Li H, Shi L. Experimental study of the heat transfer characteristics of supercritical pressure R134a in a horizontal tube. Experimental Thermal and Fluid Science. 2018.

[17] Dai X, Shi L, An Q, Qian W. Thermal stability of some hydrofluorocarbons as supercritical ORCs working fluids. Applied Thermal Engineering. 2018;128:1095-101.

[18] Cao Yaxi, Li Yonghua, Cao Jinrong. Cause analysis and countermeasures of heat exchanger tube cracking. China Special Equipment Safety. 2016;32:47-9.(In Chinese)

[19] Li Z. Heat Transfer to Supercritical Fluids in Smooth Tubes and Internally Ribbed Tubes under Circumferentially Uniform and Non-uniform Heating [Ph.D. Thesis]. Beijing: Beijing : Tsinghua university; 2015.

[20] Shen Z, Yang D, Li Y, Liang Z, Wan L. Numerical analysis of heat transfer to water flowing in rifled tubes at supercritical pressures. Applied Thermal Engineering. 2018;133:704-12.

[21] Li Z, Wu Y, Tang G, Lu J, Wang H. Numerical analysis of buoyancy effect and heat transfer enhancement in flow of supercritical water through internally ribbed tubes. Applied Thermal Engineering. 2016;98:1080-90.

[22] Menter FR. Two-equation eddy-viscosity turbulence models for engineering applications. AIAA Journal. 1994;32:1598-605.

[23] Wang D, Tian R, Zhang Y, Li LL, Ma Y, Shi L, Li H. Heat transfer investigation of supercritical R134a for trans-critical organic Rankine cycle system. Energy.

[24] Jackson J, Hall W. Turbulent forced convection in channels and bundles V1. by KAKAC, S, SPALDING, DB. 1979;2:563- 